\title{
Molecular and phylogenetic characterization of the homoeologous EPSP Synthase genes of allohexaploid wheat, Triticum aestivum (L.)
}

\author{
Attawan Aramrak', Kimberlee K. Kidwell ${ }^{1}$, Camille M. Steber ${ }^{1,2^{*+}}$ (D) and lan C. Burke ${ }^{1 *^{*}}$
}

\begin{abstract}
Background: 5-Enolpyruvylshikimate-3-phosphate synthase (EPSPS) is the sixth and penultimate enzyme in the shikimate biosynthesis pathway, and is the target of the herbicide glyphosate. The EPSPS genes of allohexaploid wheat (Triticum aestivum, AABBDD) have not been well characterized. Herein, the three homoeologous copies of the allohexaploid wheat EPSPS gene were cloned and characterized.

Methods: Genomic and coding DNA sequences of EPSPS from the three related genomes of allohexaploid wheat were isolated using PCR and inverse PCR approaches from soft white spring "Louise'. Development of genomespecific primers allowed the mapping and expression analysis of TaEPSPS-7A1, TaEPSPS-7D1, and TaEPSPS-4A1 on chromosomes 7A, 7D, and 4A, respectively. Sequence alignments of CDNA sequences from wheat and wheat relatives served as a basis for phylogenetic analysis.
\end{abstract}

Results: The three genomic copies of wheat EPSPS differed by insertion/deletion and single nucleotide polymorphisms (SNPS), largely in intron sequences. RT-PCR analysis and CDNA cloning revealed that EPSPS is expressed from all three genomic copies. However, TaEPSPS-4A1 is expressed at much lower levels than TaEPSPS-7A1 and TaEPSPS-7D1 in wheat seedlings. Phylogenetic analysis of 1190-bp cDNA clones from wheat and wheat relatives revealed that: 1) TaEPSPS-7A1 is most similar to EPSPS from the tetraploid AB genome donor, T. turgidum ( $99.7 \%$ identity); 2) TaEPSPS-7D1 most resembles EPSPS from the diploid D genome donor, Aegilops tauschii (100\% identity); and 3) TaEPSPS-4A1 resembles EPSPS from the diploid B genome relative, Ae. speltoides (97.7 \% identity). Thus, EPSPS sequences in allohexaploid wheat are preserved from the most two recent ancestors. The wheat EPSPS genes are more closely related to Lolium multiflorum and Brachypodium distachyon than to Oryza sativa (rice).

Conclusions: The three related EPSPS homoeologues of wheat exhibited conservation of the exon/intron structure and of coding region sequence, but contained significant sequence variation within intron regions. The genome-specific primers developed will enable future characterization of natural and induced variation in EPSPS sequence and expression. This can be useful in investigating new causes of glyphosate herbicide resistance.

Keywords: Cloning, EPSP synthase, Glyphosate, Polyploid, TaEPSPS-4A1, TaEPSPS-7A1, TaEPSPS-7D1, Triticeae evolution, Triticum aestivum, Wheat

\footnotetext{
* Correspondence: csteber@wsu.edu; icburke@wsu.edu

${ }^{\dagger}$ Equal contributors

'Department of Crop and Soil Science, Washington State University, Pullman,

WA, USA

Full list of author information is available at the end of the article
}

\section{Biomed Central}

(c) 2015 Aramrak et al. Open Access This article is distributed under the terms of the Creative Commons Attribution 4.0 International License (http://creativecommons.org/licenses/by/4.0/), which permits unrestricted use, distribution, and reproduction in any medium, provided you give appropriate credit to the original author(s) and the source, provide a link to the Creative Commons license, and indicate if changes were made. The Creative Commons Public Domain Dedication waiver (http://creativecommons.org/publicdomain/zero/1.0/) applies to the data made available in this article, unless otherwise stated. 


\section{Background}

5-Enolpyruvylshikimate-3-phosphate synthase (EC 2.5.1.19) or EPSP synthase (EPSPS) is the sixth and penultimate enzyme in the shikimate pathway [1]. EPSPS activity and the shikimate pathway are essential for the biosynthesis of the aromatic amino acids phenylalanine, tryptophan, and tyrosine, and for various secondary metabolites derived from the precursor chorismate, such as lignin, auxin, alkaloids, carotenoids, vitamins, and phenolic compounds $[1,2]$. The synthesis of these compounds is essential to plant health and growth. EPSPS enzyme is potently inhibited by glyphosate, a non-selective herbicide widely used in weed management. A mutation in EPSPS is one mechanism conferring glyphosate resistance to weeds and crops. The amino acid substitution from proline at amino acid position 106 in EPSPS to serine, threonine, leucine, or alanine results in glyphosate resistance in weed species [3-5]. Thus, knowledge about the wheat EPSPS gene sequence, expression, exon-intron structure, and the development of genome-specific primers will be useful for examining natural and induced mutations in wheat EPSPS, as well as for detecting transgene contamination. For example, genome-specific primers and quantitative reverse transcription polymerase chain reaction (RT-qPCR) methods for measuring EPSPS mRNA levels are useful for determining if glyphosate resistance results from increased EPSPS expression levels, as previously described in Dicliptera chinensis (Chinese foldwing) [6]. The development of genome-specific primers may be useful to researchers investigating whether there are naturally occurring mutations in the wheat EPSPS genes if glyphosate resistant wheat is found in farmers' fields. It is also interesting from the perspective of investigating wheat genome evolution based on the EPSPS sequence.

Currently, there is not a transgenic glyphosateresistant wheat cultivar available for use by growers due in part to lack of acceptance by export markets. Common wheat ( $T$. aestivum) or bread wheat is one of the major food grain crops belonging to the grass Poaceae family. The hybridization between the diploid AA genome-donor and the $\mathrm{BB}$ genome-donor generated the allotetraploid T. turgidum (AABB) or durum wheat that is currently grown for use in pasta [7-9]. The diploid A-genome donor is believed to have been $T$. urartu $\left(\mathrm{A}^{\mathrm{u}} \mathrm{A}^{\mathrm{u}}\right)$, or a relative of the ancient crop plant einkorn T. monococcum $\left(\mathrm{A}^{\mathrm{m}} \mathrm{A}^{\mathrm{m}}\right)$. The diploid $\mathrm{B}$-genome donor is an unknown species (BB), but related to Ae. speltoides (SS). Subsequently, diploid Ae. tauschii (DD genomedonor) hybridized to tetraploid wheat, giving rise to the allohexaploid bread wheat (AABBDD). The large 17gigabase allohexaploid wheat genome is comprised of 21 chromosomes $(1 n)$ with three sets of 7 chromosomes derived from each related (homoeologous) subgenome (A, B, and D) of the three diploid ancestors [7-10].
The 21 wheat chromosomes are designated based on the 7 homoeologous chromosome group and three genomes, such that we refer to chromosome 1A, 1B, 1D through chromosome 7A, 7B, and 7D. Allohexaploid wheat behaves like a diploid during meiosis such that chromosome 7A can only pair with 7A, not with 7B or 7D. The wheat genome has also evolved through translocation events [11]. For example, a segment of chromosome $7 \mathrm{BS}$ translocated to $4 \mathrm{AL}$, and a segment of $4 \mathrm{AL}$ translocated to 5AL. Both gene cloning and gene expression analysis in wheat are complicated by the inherent genetic redundancy and by a large portion (more than $80 \%)$ of non-coding DNA $[8,12]$. Consequently, development of high quality genome-specific primers for wheat genes of interest is essential.

The EPSPS enzymes of different species are divided into two classes according to glyphosate sensitivity. The Class I EPSPS enzymes found in plants and bacteria (i.e. Escherichia coli and Salmonella typhimurium) are glyphosate sensitive and have been used to characterize the enzyme kinetics and active site [13]. The Class II EPSPS found in bacterial species including Agrobacterium tumefaciens sp. strain CP4, Pseudomonas sp. strain PG2982, and Staphylococcus aureus are glyphosate resistant and have been used to develop glyphosate-resistant crops [14]. The EPSPS of plants is nuclear-encoded but functions in the chloroplast. Thus, the premature EPSPS polypeptide contains an $\mathrm{N}$-terminal transit peptide signal that is cleaved upon transport into the chloroplast [1].

Wheat EPSPS primers for PCR cloning based upon the EPSPS mRNA sequence of Chinese Spring wheat and upon wheat expressed sequence tag (EST) sequences were developed as part of this work. PCR is a simple and powerful technique used in molecular studies such as gene cloning, gene expression analysis, and disease diagnosis. PCR approaches have been successfully used in the isolation of homoeologous genes from hexaploid wheat and in quantification of gene expression from related genomes of hexaploid wheat [15-17]. The development of wheat genome-specific primers has been challenging due to: (i) the large portion of non-coding DNA in the wheat genome, (ii) the low level of polymorphism in the coding sequences of wheat homoeologues, and (iii) the lack of a reference genome sequence. The recent publication of the $0.6 \mathrm{X}$ draft genome sequence of Chinese Spring wheat and of the 'Kukri' wheat transcript assembly will help future wheat cloning efforts $[18,19]$.

Herein, we cloned the TaEPSPS-7A1, TaEPSPS-7D1, and TaEPSPS-4A1 genes from the allohexaploid spring wheat cultivar 'Louise', as well as the homologous EPSPS cDNA sequences of four wheat progenitors. This allowed us to examine the evolution of the wheat EPSPS gene based on phylogenetic sequence analyses. The development of genome-specific EPSPS primers allowed us to 
examine the chromosome location of the wheat EPSPS genes and to compare the expression levels of the three homoeologous wheat EPSPS transcripts.

\section{Results and discussion Initial cDNA cloning revealed two major expressed homoeologous EPSPS genes}

Preliminary experiments cloned wheat EPSPS cDNA sequences using primer pairs designed based on an alignment of two $T$. monococcum and thirteen $T$. aestivum (Chinese Spring) ESTs to amplify EPSPS sequence from all three wheat genomes (Table 1; Additional file 1). Cloning and sequencing of cDNA from allohexaploid wheat 'Louise' and from the wheat relatives T. monococcum, Ae. speltoides, Ae. tauschii, and T. turgidum was used to determine which primer pair could amplify the largest cDNA fragment from all wheat genomes and relatives. RT-PCR amplification with primer pairs F2R2, F2-R3, and F2-R1 produced products from all lines but for Ae. speltoides, whereas F3-R2, F3-R3, and F3-R1 produced products from all genotypes including Ae. speltoides. The F3-R1 primer pair was selected for use in cDNA cloning because it produced the largest fragment, 1190-bp, containing the EPSPS coding region from exons 2 to 8 based on alignment with rice EPSPS [GenBank:AF413081].

The 1190-bp EPSPS cDNA clones from the wheat species above were sequenced and aligned. Consensus sequences were derived from eleven independent clones from allohexaploid wheat and from three independent clones from each wheat progenitor (Fig. 1; Additional file 2). The 1190-bp cDNA clones from the same species had 96-100\% nucleotide identity. Allohexaploid wheat was expected to have three functional copies of EPSPS, one each on the A, B, and D genomes [20]. The cDNA alignment revealed that there were two clusters of EPSPS cDNA sequences, one with high homology to the D genome donor Ae. tauschii (5 clones called "EPSPSD", 99.9-100\% sequence identity) and one with high homology to $T$. turgidum (4 clones called "EPSPS$A B$ ", 99.2-99.7 \% sequence identity) (Additional file 2). The remaining two clones, T.a_cDNA9 and T.a_cDNA7 appeared to be chimeras, and may either be PCR artifacts or may represent EPSPS-related sequence from the wheat genome. The preliminary identification of the wheat EPSPS- $A B$ and EPSPS-D CDNA sequences allowed the design of genome-specific primers using sequences containing multiple point mutation differences (Table 1; Additional files 1 and 3). Mapping later revealed that the EPSPS-AB primer pair F18-AB-R16-AB amplified TaEPSPS-7A1 (T. aestivum 5-enolpyruvylshikimate-3phosphate synthase) on chromosome 7A, and the EPSPS-D primer pair F18-D-R16-D amplified TaEPSPS-7D1 on chromosome 7D (described below).

\section{Molecular cloning of a full-length genomic clone of TaEPSPS-7A1}

In the cDNA cloning experiment, no primers upstream of F3 amplified the 5' region of EPSPS, likely because it is highly GC-rich ( $82 \%)$. The primer F1.2 was designed to amplify this region upstream of F3 (Fig. 2). Eight different buffers designed to enhance the amplification efficiency of GC-rich targets were tested using the primer pair F1.2-R1 for PCR amplification of EPSPS from genomic DNA (see Methods; Fig. 3; Additional files 1, 3, and 4). Based on the rice EPSPS gene, the full length wheat EPSPS genomic clone was expected to be approximately 3.6-kb. PCR amplification with F1.2-R1 recovered 3.3-kb, 2-kb, $1.2 \mathrm{~kb}$, and 0.9-kb products. Cloning and sequencing revealed that the $2-\mathrm{kb}, 1.2-\mathrm{kb}$, and $0.9-\mathrm{kb}$ products contained no homology to EPSPS. All of the four independent 3.3-kb clones contained a 3345-bp sequence with high identity (>99\%) to the EPSPS-AB cDNA clones. The 3345-bp consensus sequence, designated TaEPSPS-7A1 [GenBank:KP411547], appeared to contain the full length wheat coding sequence based on alignment with rice EPSPS (O. sativa EPSPS or OsEPSPS) (Fig. 2). Based on alignment with the wheat EPSPS-AB cDNA and OsEPSPS, TaEPSPS-7A1 is spliced into a 1533-bp cDNA encoding a predicted 510 amino acid protein with $87.3 \%$ amino acid identity to OsEPSPS (Figs. 1 and 2; Table 2; Additional file 5).

\section{Isolation of TaEPSPS-7D1 and TaEPSPS-4A1}

Polymorphic intron and exon sequences were used to develop genome-specific primers to clone and map the TaEPSPS-7D1 and TaEPSPS-4A1 genes (Table 1; Additional files 1 and 4) [21]. PCR amplification using Louise genomic DNA and the primer-pair combinations F13-AB-R1, F14-D-R1, and F3-R2 recovered EPSPS sequences containing polymorphisms compared to TaEPSPS-7A1. The F14-D-R1 primer pair amplified 600-bp and 838-bp, F13-AB-R1 amplified a 647-bp, and F3-R2 amplified a 838-bp product. The 600-bp (F14-D-R1) and 838-bp (F3-R2) products shared exon regions with $100 \%$ identity to the 1190-bp EPSPS-D and of Ae. tauschii cDNA sequences (Table 1; Additional files 1, 2, and 4). Thus, two partial TaEPSPS-7D1 genomic clones were identified. Cloning and sequencing revealed that the 647-bp (F13-AB-R1) product was a partial genomic clone of TaEPSPS-4A1 based on lack of homology to TaEPSPS-7A1 and the TaEPSPS-7D1. Attempts to amplify the 5' genomic region of the TaEPSPS-7D1 and TaEPSPS-4A1 open reading frame (ORF) using combinations of F1.2 and several reverse primers designed to be $4 \mathrm{~A}$ - and $7 \mathrm{D}$-specific based on intronic sequences failed to recover a product, suggesting that the F1.2 primer is specific to TaEPSPS$7 A 1$ (data not shown). 
Table 1 Primer sequences and primer positions based on TaEPSPS-7A1

\begin{tabular}{|c|c|c|c|c|}
\hline aprimer No. & Primer name & 'bequence (5' to 3') & ${ }^{\complement}$ Genome specificity & Primer position \\
\hline \multicolumn{5}{|l|}{ Forward } \\
\hline- & $\mathrm{T7}$ & TAATACGACTCACTATAGGG & - & - \\
\hline 1 & $\mathrm{~F} 1.2$ & GCAATGGCGATGGCTG & $7 A$ & 5'-UTR/exon 1 \\
\hline 2 & Int1_F2-D & AGCAGCATGTCCTGTTATCTTAT & 7D & intron 1 \\
\hline 3 & Int1_F2-A/B & CAGCATGTCCTGTTCTCTTG & $4 \mathrm{~A}$ & intron 1 \\
\hline 4 & $\mathrm{~F} 2$ & AGGATGTCCACTACATGCTT & $7 A / 7 D$ & exon 2 \\
\hline 5 & F3 & AGGATGTCCACTACATGCTC & 7D/4A/7A & exon 2 \\
\hline 6 & $F 2-A B$ & GCAACTTATGTGCTTGATGGC & $7 A$ & exon 2/exon 3 \\
\hline 7 & $\operatorname{lnvF1-AB/D}$ & GAGCGACCTATTGGTGACTTAG & 7D/7A/4A & exon 3 \\
\hline 8 & $\operatorname{lnvF3-AB/D}$ & CCACCTGTCCGTATCAACG & 7A/7D/4A & exon 3 \\
\hline 9 & Int3_F1-AB & ATGTAATGCAACCTTAGACCGC & $7 A$ & intron 3 \\
\hline 10 & Int3_F1-A/B & CGATCAATGCGACCTTACACAAT & $4 A$ & intron 3 \\
\hline 11 & Int3_F1-D & GCAACGCGACCTTACACCGT & 7D & intron 3 \\
\hline 12 & F19-AB & GGACAGATTCTACATTAAGGGAGGAC & 7D/7A/4A & exon 4 \\
\hline 13 & Ex6_B-F & TACTTGAGATGATGGGAGCG & $4 A$ & exon 6 \\
\hline 14 & $F 13-A B$ & ATTGGAAGGAAACACCTAAAA & $7 A / 4 A$ & exon 6 \\
\hline 15 & F14-D & GAAGGAAACACTTAAAGGCTGTC & 7D & exon 6 \\
\hline 16 & F19-D & GTCCTGACACTTGTTCATTC & $7 D / 4 A$ & intron 6 \\
\hline 17 & $F 18-A B$ & GAACATCACGGCGATCGAC & $7 A / 4 A$ & exon 8 \\
\hline 18 & F18-D & GAACGTCACGGCGATCGAT & 7D & exon 8 \\
\hline- & TaSEC_F & AGCAATTCGCACAATTATTACAAG & - & - \\
\hline \multicolumn{5}{|l|}{ Reverse } \\
\hline- & SP6 & TATTTAGGTGACACTATAG & - & - \\
\hline 19 & InvR2-AB-D & CAACAGGTTATCCACCACC & common & exon 2 \\
\hline 20 & InvR1-AB-D & GCATTGCAGTTCCAGCATTAC & common & exon 2 \\
\hline 21 & $\mathrm{R} 1-\mathrm{AB}$ & TTGTGCCAAGGAAACAATCGA & $7 A$ & exon 3 \\
\hline 22 & Ex4_R2 & GCTCCGCAGTCACACCAAAAT & $7 A$ & exon 4 \\
\hline 23 & R2 & TCAGAATGCTCCGCAGTCACA & $7 A / 7 D$ & exon 4 \\
\hline 24 & R3 & TCAGAATGCGCCGCAGTCACG & $7 D / 4 A$ & exon 4 \\
\hline 25 & Ex4_R3 & CTTGTATITTTGTCCTCCCTTG & $4 A$ & exon 4 \\
\hline 26 & R19-AB & CCAGAATAATGGATGGCTCG & $7 A$ & intron 4 \\
\hline 27 & Ex6_B-R1 & GCAACAACGGCAAGAGTCATT & $4 A$ & exon 6 \\
\hline 28 & R18-D & GACGCACGTGCTAGATTGCTTG & 7D & intron 6 \\
\hline 29 & $\mathrm{R} 12-\mathrm{AB}$ & CGGATCGCGACCATTCTTTCA & $7 A$ & exon 7 \\
\hline 30 & R16-AB & TCTTTCGGGTGCATCCAGGG & $7 A$ & exon 8 \\
\hline 31 & R16-D & TCTTTCTGGTGCACCCCGGA & 7D & exon 8 \\
\hline 32 & R1 & CTAGTTCTTGACGAAGGTGCTTAG & common & exon 8 \\
\hline- & TaSEC_R & CTCACAGAAGACCTGGAAGC & - & - \\
\hline
\end{tabular}

aprimers are numbered in order based on location in TaEPSPS-7A1 as shown in Additional file 4

${ }^{\mathrm{b}}$ The start codon ATG and stop codon CTA are underlined

${ }^{\mathrm{C}}$ Bold letters indicate genome-specific primers

Nested inverse-PCR (IPCR) strategies were devised to clone the remaining genomic sequences of TaEPSPS-7D1 and TaEPSPS-4A1 (Additional files 1 and 4) [22, 23]. Primers were developed for the D genome copy based on the 600-bp (F14-D-R1) TaEPSPS-7D1 clone, and for the TaEPSPS-4A1 based on the 647-bp product. TaEPSPS$7 D 1$ genomic sequence was recovered from F18-D-R18-D amplification of circularized AccI-digested genomic DNA. 


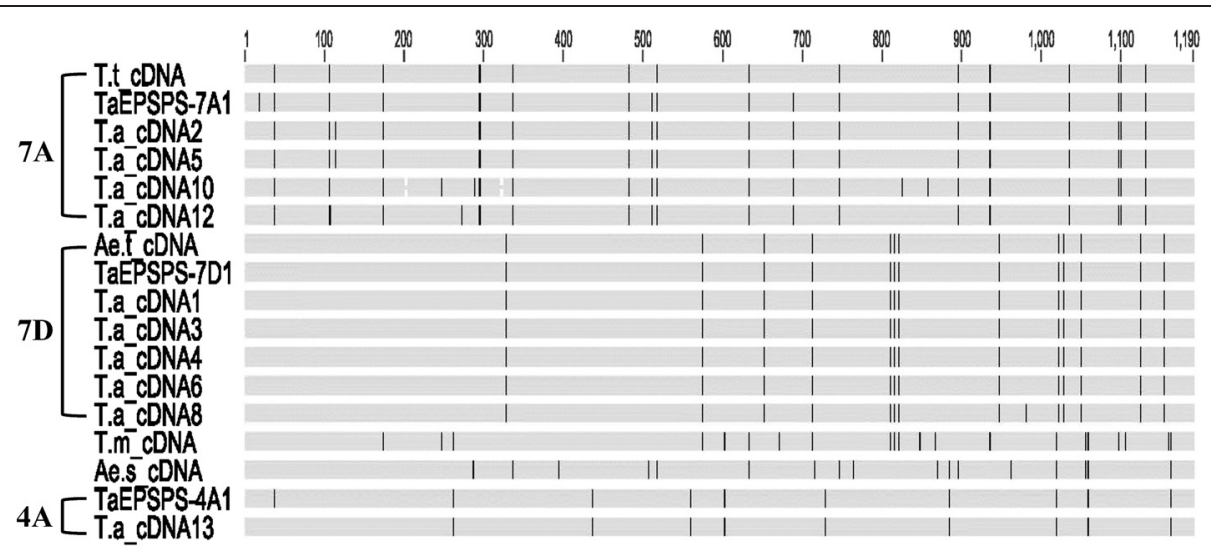

Fig. 1 Nucleotide polymorphisms from an alignment of EPSPS CDNA sequences of allohexaploid wheat and wheat progenitors. Vertical lines in the diagram indicate the position of nucleotide polymorphisms identified in a ClustalW multiple sequence alignment of the 1190-bp cDNA clones from T. aestivum 'Louise' (T.a_cDNA\#), with our 1190-bp cDNA consensus sequences for T. turgidum (AB progenitor) (T.t_cDNA), Ae. tauschii (D progenitor) (Ae.t_cDNA), T. monococcum (A-relative) (T.m_cDNA), and Ae. speltoides (B-relative) (Ae.s_cDNA). The equivalent 1190-bp sequence of the genomic DNA consensus sequences of "TaEPSPS-7A1, TaEPSPS-7D1, and TaEPSPS-4A1" are shown with intron sequences removed. Only the TaEPSPS-7A1 and TaEPSPS-7D1 CDNAs were recovered by F3-R1 PCR amplification. The corresponding 1190-bp TaEPSPS-4A1 CDNA sequence (T.a_CDNA13) was derived from an independent experiment

The resulting 1261-bp clone included 1114-bp of TaEPSPS-7D1 plus 147-bp of 7D chromosome sequence flanking the 3 'end of the TaEPSPS-7D1 gene. InvF3-AB-InvR2-AB amplification of the HindIII- and AccI-digested DNA template recovered 702-bp and 682-bp products, respectively. The 702-bp product overlapped with the TaEPSPS-7D1 genomic sequence, whereas the 682-bp (AccI) fragment contained TaEPSPS$4 A 1$ sequences.

Genome-specific primers were designed for PCR amplification of longer genomic clones of the TaEPSPS-4A1
(Int1_F2-A/B-R1 amplified the 2597-bp clone, Int3_F1A/B-R1 the 1918-bp clone) and TaEPSPS-7D1 (Int1_F2D-R1 amplified the 2554-bp clone, Int3_F1-D-R1 the 1868-bp clone). Sequencing of these clones in both directions recovered the missing genomic sequences of both TaEPSPS-7D1 and TaEPSPS-4A1 (Additional files 1 and 4). Thus, we recovered the genomic sequences of TaEPSPS-7D1 [GenBank:KP411548] and of TaEPSPS$4 A 1$ [KP411549] including a partial sequence for intron 1 and complete sequences for the remaining introns and for exons 2 through 8 .

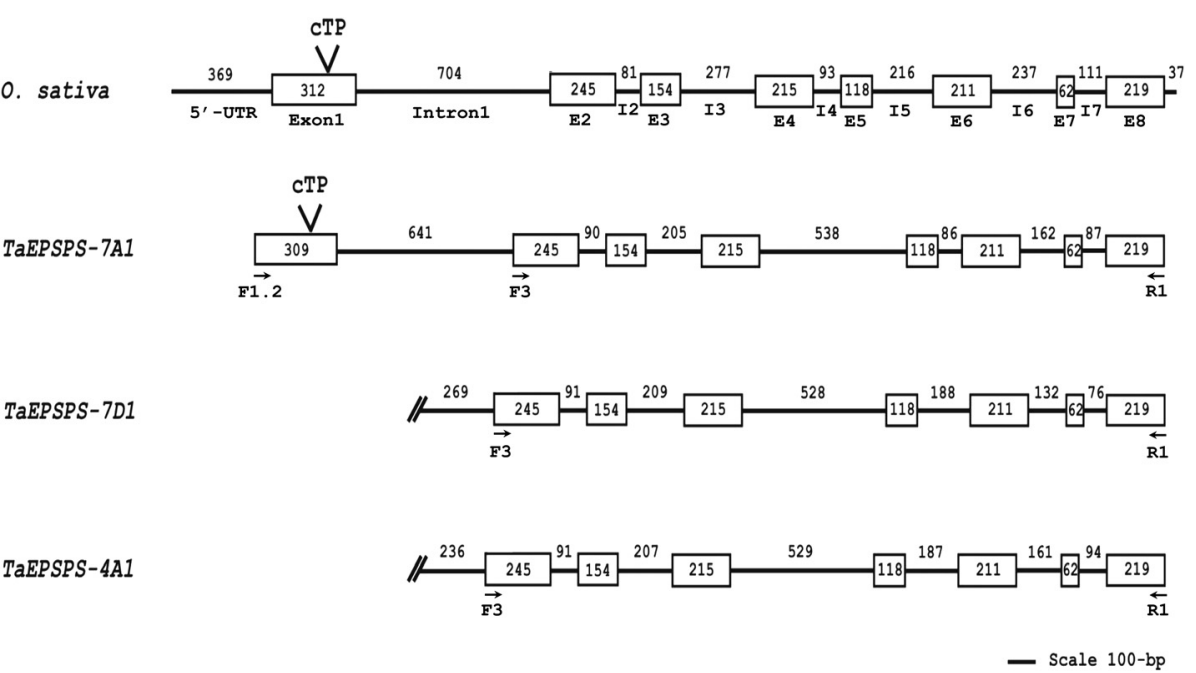

Fig. 2 Exon-intron structure of the wheat EPSPS genes compared to OsEPSPS. The boxes and solid lines represent exons (E\#) and introns (I\#), respectively. Numbers indicate exon and intron size in bp. The cleavage site of the chloroplastic transit signal peptide (cTP) predicted by PredSL is shown. The positions of the primers F1.2, F3, and R1 (arrows) used for initial genomic and cDNA cloning are labeled 


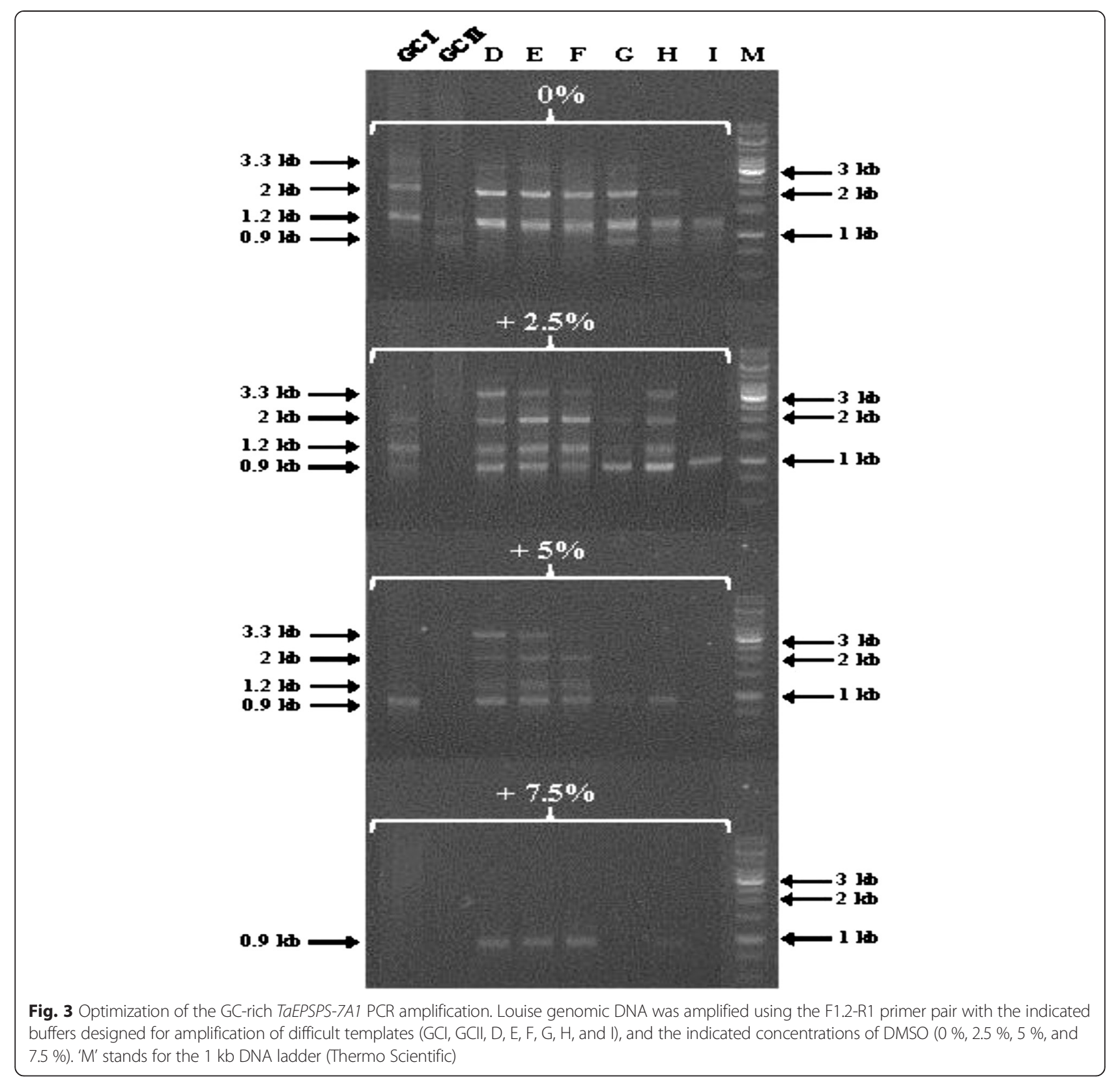

Table 2 Percent homology of EPSPS sequences

\begin{tabular}{|c|c|c|c|c|c|}
\hline \multirow[t]{2}{*}{ Alignment levels } & \multicolumn{5}{|c|}{$\%$ Homology $^{a}$} \\
\hline & $7 \mathrm{~A} 1 / 7 \mathrm{D} 1^{\mathrm{b}}$ & $7 \mathrm{~A} 1 / 4 \mathrm{~A} 1$ & 7D1/4A1 & $7 \mathrm{~A} 1 / \mathrm{Os}$ & 7A1/CP4 \\
\hline Genomic DNA sequence & 84.7 & 85.7 & 93.8 & 62.3 & 39.3 \\
\hline cDNA sequence & 96.3 & 96.6 & 97.4 & 83.5 & 41.4 \\
\hline Amino acid sequence & 99.3 & 99.0 & 99.8 & 87.3 & 23.0 \\
\hline
\end{tabular}

${ }^{a}$ Based on alignment of corresponding regions of exon 2 through exon 8

${ }^{\mathrm{b}}$ Abbreviaitons: 7A = TaEPSPS-7A1; 7D = TaEPSPS-7D1; 4A = TaEPSPS-4A1; Os = OsEPSPS [GenBank:AF413081, AAL06593]; CP4 = Agrobacterium CP4 EPSPS [AB209952, BAD94823] 


\section{Determining the chromosome location of the wheat EPSPS genes}

PCR amplification of genomic DNA from nulli-tetrasomic Chinese Spring wheat lines was used to determine the chromosome location and to confirm primer specificity during the cDNA and genomic cloning of TaEPSPS-7A1, TaEPSPS-4A1, and TaEPSPS-7D1 (see Methods) [16]. For mapping, PCR amplification of nulli-tetrasomic genomic DNA was performed using gene-specific primers (Fig. 4; Additional file 1). The location of each EPSPS copy was defined based on failed PCR amplification in a specific nulli-tetrasomic line. Primers for the TaEPSPS-7D1 failed to show amplification using the nulli7D-tetra7B (no copies $7 \mathrm{D}, 4$ copies 7B) as the genomic DNA template. Similarly, the TaEPSPS-4A1 and TaEPSPS-7A1 primers failed to amplify using the nulli4A-tetra4D (no copies $4 \mathrm{~A}, 4$ copies 4D) and the nulli7A-tetra7D (no copies 7A, 4 copies 7D) as template, respectively. Thus, each wheat EPSPS clone was identified based on its chromosome location on 7A, $4 \mathrm{~A}$, and 7D, respectively.

Homoeologous genes of common wheat are usually located on the same group of chromosomes. For example, the wheat PDI (protein disulfide isomerase) homoeologues positioned on group 4 (4A, 4B, 4D), DMC1 (RecA protein) on group 5, and RAD51 (RecA protein) and SSII (starch synthase II) on group $7[15,17,21]$. The three wheat EPSPS genes belong to homoeologous group 7, since the allohexaploid wheat genome contains a chromosomal translocation from chromosome $7 \mathrm{BS}$ onto 4AL that occurred in the tetraploid ancestor [11]. We identified clones with high identity to TaEPSPS-7A1, TaEPSPS-7D1, and TaEPSPS-4A1 on chromosomes 7AS, 7DS, and 4AL, respectively, in the $0.6 \mathrm{X}$ draft Chinese Spring wheat genome sequence [18]. This confirmed the chromosomal location of the wheat EPSPS genes.

We also observed that the TaEPSPS-7A1 primers failed to amplify a PCR product from the nulli5B-tetra5D line (no copies 5B, 4 copies 5D) (Fig. $4 \mathrm{~b}$ and c). No homologue of TaEPSPS-7A1 was identified on chromosome $5 \mathrm{~B}$ of the $0.6 \mathrm{X}$ Chinese Spring draft sequence. Moreover, there could not be a copy of TaEPSPS-7A1 on chromosome $5 \mathrm{~B}$ because such a duplication would resulted in presence of a TaEPSPS-7A1 PCR product in both the nulli7A-tetra7D and nulli5B-tetra5D lines. Thus, it appears that the nulli5B-tetra5D line contained a deletion of the TaEPSPS-7A1 gene. Consistent with this reasoning, a previous study of chromosome aberrations in nulli-tetrasomic lines showed that the nulli5Btetra5D line contains a deletion in the chromosome 7AS region that likely contains TaEPSPS-7A1 [24].

The cloning experiments described here were initiated before publication of the $0.6 \mathrm{X}$ Chinese Spring draft sequence, and provide new sequence and expression information [18]. The Chinese Spring TaEPSPS-7A1, TaEPSPS-7D1, and TaEPSPS-4A1 genomic DNA contigs were incomplete (see Contigs 7AS_59852, 7AS_4136845, 7DS_3942167 and 7DS_3891840, and 4AL_7136532 and 4AL_7168802). They included a partial sequence of intron

\section{D (exon 8) \\ (B) F18-AB-R16-AB $7 A$ (exon 8) \\ (C) Int3_F1-AB-Ex4_R2 $7 A$ (intron 3/exon 4) \\ (D) Int3_F1-A/B-Ex4_R3 $4 A$ (intron 3/exon 4) \\ (E) Ex6_B-F-Ex6_R1 4A (exon 6)}

(A) F18-D-R16-D

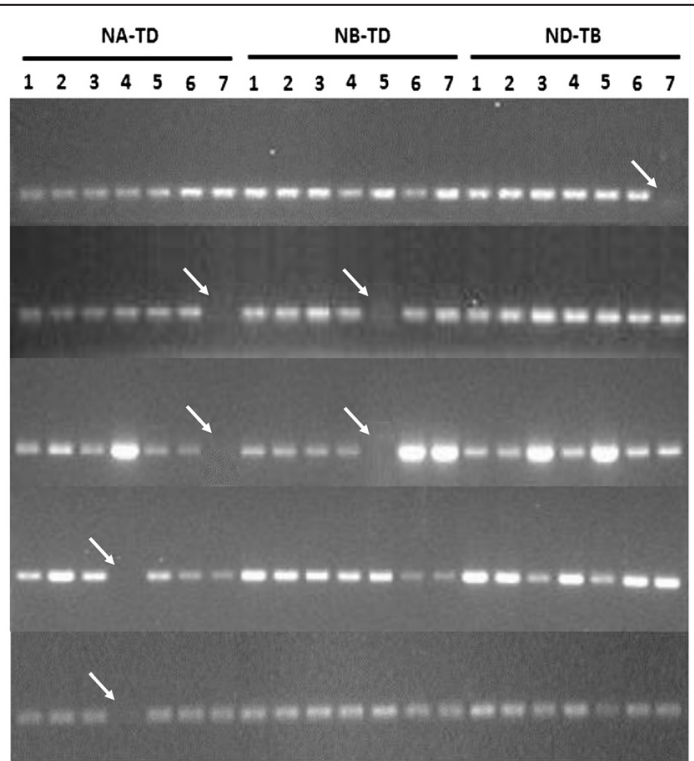

Fig. 4 Mapping the chromosome locations of the wheat EPSPS genes using nulli-tetrasomic lines. PCR amplification was performed using indicated Chinese Spring nulli-tetrasomic genomic DNA. These lines contain no copy of one chromosome (nullisomic), and 4 doses (tetrasomic) of a homoeologous chromosome. The lines are referred to as nulli1A-tetra1D or N1A-T1D, N2A-T2D, etc. DNA was amplified with the indicated primer pairs for: a TaEPSPS-7D1 failed to amplify in N7D-T7B line with primers F18-D-R16-D indicating localization to chromosome 7D; (b and c) TaEPSPS-7A1 failed to amplify in N7A-T7D with indicated primers; (d and e) TaEPSPS-4A1 failed to amplify in N4A-T4D 
1 and genomic sequence downstream of intron 1 , but lacked the GC-rich exon 1 sequence recovered here for TaEPSPS-7A1 from Louise spring wheat. IWGSC recovered two overlapping cDNA clones (1158-bp) with 95.4-99.8 \% similarity to TaEPSPS-7A1, but did not recover cDNA clones for TaEPSPS-7D1 and TaEPSPS-4A1. The TaEPSPS-7D1 and TaEPSPS-4A1 cDNA clones recovered in the current study proved that these genes are expressed.

\section{Recovery of CDNA sequence of TaEPSPS-4A1}

The cDNA clones of TaEPSPS-7A1 and TaEPSPS-7D1, but not of TaEPSPS-4A1, were recovered from total seedling RNA by RT-PCR amplification with the F3-R1 primer pair. Based on the genomic sequence, the F3-R1 primers should also amplify the TaEPSPS-4A1 cDNA. To determine whether TaEPSPS-4A1 is a pseudogene or a low-abundance transcript, we attempted to clone the TaEPSPS-4A1 cDNA using gene-specific primer pairs. F3-Ex6_B-R1 and Ex6_B-F-R1 amplified 874-bp and 470bp products respectively, using 'Louise' cDNA as a template (Table 1; Additional file 1). Five independent clones from each product were sequenced. All 470-bp clones had $100 \%$ identity to the TaEPSPS-4A1 exon sequences. The F3-Ex6_B-R1 primers were less TaEPSPS-4A1-specific, since one 874-bp clone corresponded to TaEPSPS-4A1, three to TaEPSPS-7D1, and one to TaEPSPS-7A1. The complete 1190-bp TaEPSPS-4A1 cDNA sequence was derived from the two overlapping 874-bp and 470-bp clones (T.a_cDNA13 in Fig. 1; Additional file 1). Thus, TaEPSPS$4 A 1$ may be expressed at lower levels than TaEPSPS-7A1 and TaEPSPS-7D1 in seedlings.

\section{Expression levels of the three wheat EPSPS homoeologues}

We examined the relative expression levels of TaEPSPS7A1, TaEPSPS-7D1, and TaEPSPS-4A1 in seedlings using RT-qPCR analysis. Expression was examined at the 3 to 5leaf stage because glyphosate is typically foliar-applied to young seedlings, and because EPSPS expression can be higher in leaves than in roots [25]. RT-qPCR analysis revealed that all three wheat EPSPS transcripts were actively expressed, but accumulated at different levels (Fig. 5; Additional file 1). The TaEPSPS-7A1 transcript was most highly expressed, showing 3-fold higher expression than TaEPSPS-7D1 and almost 9-fold higher expression than TaEPSPS-4A1 (P-value <0.001). The TaEPSPS-4A1 mRNA levels were significantly lower than TaEPSPS-7D1 $(P$-value $=0.003)$. The relatively low TaEPSPS-4A1 mRNA levels were consistent with the difficulty recovering the TaEPSPS-4A1 cDNA using the F3-R1 primer pair that was able to bind all three transcripts.

The differential expression of TaEPSPS-7A1, TaEPSPS$7 D 1$, and TaEPSPS-4A1 may have evolved after the

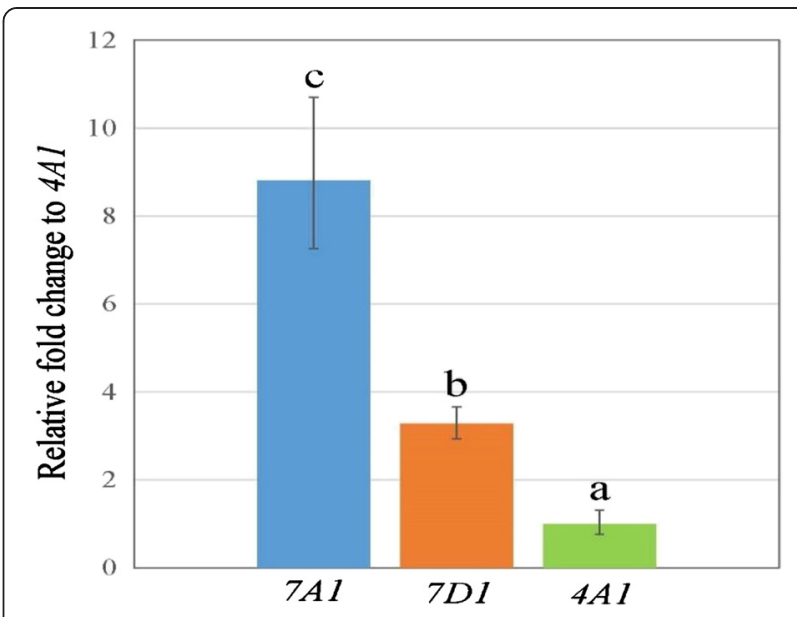

Fig. 5 RT-qPCR analysis of wheat EPSPS gene expression in seedlings. The relative expression levels of TaEPSPS-7A1 (7A1), TaEPSPS-7D1 (7D1), and TaEPSPS-4A1 (4A1) were determined by RT-qPCR using genomespecific primers (Additional file 1). The fold change was calculated relative to the TaEPSPS-4A1 mRNA level (set to 1) using the comparative $C_{q}$ method. Letters $(a, b$, and $c)$ represent significant differences ( $P<0.005$, based on a one-way ANOVA with Tukey's adjustment at the $99 \%$ significance level). Bars indicate the standard error

polyploidization event. Previous studies have examined wheat gene expression in synthetic allohexaploid wheat generated through man-made polyploidization events. In such synthetic allohexaploids, as many as $87 \%$ of wheat genes were expressed at similar levels from the A, B, and $\mathrm{D}$ genomes, although sometimes there was expression predominantly from one or two homoeologues $(2.9 \%)[26,27]$. A homoeologue may be lost through deletion or may become silenced during wheat genome evolution [20, 27]. Moreover, differential regulation may result from evolution of regulatory mechanisms through mutations in promoters or enhancer regions [26, 28, 29].

\section{Sequence comparison and gene structure}

Cloning of the cDNA and genomic clones for TaEPSPS7A1, TaEPSPS-7D1, and TaEPSPS-4A1 allowed us to compare the sequence and intron/exon structures of the three wheat EPSPS homoeologues (Fig. 2; Additional file 3). The complete TaEPSPS-7A1 coding sequence (7 introns/8 exons) was cloned, including the 3342-bp ORF, and the 1533 -bp cDNA encoding a predicted 510 amino acid protein $(53.8 \mathrm{kDa})$. The TaEPSPS-4A1 (2729-bp) and TaEPSPS-7D1 (2717-bp) genomic clones included all intron and exon sequences except exon 1 and a portion of intron 1. Based on the 1190-bp cDNA and incomplete genomic sequences of TaEPSPS-7D1 and TaEPSPS-4A1, we can derive partial 1224-bp cDNA sequences containing exons 2 through 8 , but not exon 1 . The 1224-bp cDNA partial sequence encodes a predicted 407 amino acid EPSPS enzyme (43.4 kDa TaEPSPS-4A1 and $43.5 \mathrm{kDa}$ TaEPSPS-7D1) (Additional file 5). The wheat 
EPSPS proteins show higher homology to the glyphosatesensitive Class I EPSPS of rice (87.3\% identity) than to the glyphosate-resistant Class II EPSPS of CP4 (23\% identity) (Table 2) [25].

Based on previous characterization of EPSPS in Amaranthus palmeri, Petunia hybrida, and Arabidopsis thaliana, we expected exon 1 to contain the chloroplastic signal peptide [30,31]. EPSPS is a nuclear-encoded protein that must be transported to the chloroplast. The chloroplastic transit signal peptide of the EPSPS protein sequence is cleaved once the protein is located in the chloroplast [1]. PredSL was used to search for the expected chloroplastic signal peptide [32]. A chloroplastic signal peptide was detected in exon 1 of TaEPSPS-7A1 (Additional file 6). These signal peptide amino acid sequences were highly conserved in other grasses including B. distachyon, O. sativa, Sorghum halepense, and Zea mays. Based on the cleavage point for the chloroplastic signal peptide, the cloned regions of the TaEPSPS-4A1 and TaEPSPS-7D1 include all but the first 32 amino acids of the enzyme.

The gene structure of each EPSPS copy was originally predicted using NetGene 2 and Neutral Network splicejunction analysis programs [33, 34], and then confirmed by comparing genomic and cDNA sequences (Fig. 2). When the genomic and cDNA sequences were aligned using the Geneious ${ }^{\mathrm{Tm}}$ Global Alignment tool, the actual splice junctions were identical to those predicted and to those of rice and A. palmeri [GenBank:AF413081, FJ861242.1] [30, 35]. There was a higher frequency of SNP and In/Del variation within intron than exon sequences among the three wheat EPSPS sequences (Fig. 1; Additional file 3). At the genomic DNA level, TaEPSPS$7 D 1$ had higher homology to TaEPSPS-4A1 (93.8 \% identity) than to TaEPSPS-7A1 (84.7\% identity) (Table 2). The three wheat EPSPS homoeologues were very similar, with more than $96 \%$ and $99 \%$ identity at the cDNA and amino acid levels, respectively.

\section{Phylogenetic analysis of the EPSPS genes of allohexaploid wheat}

Phylogenetic analyses of wheat EPSPS were conducted using the 1190-bp cDNA sequences of TaEPSPS-7A1, TaEPSPS-7D1, and TaEPSPS-4A1, and of the wheat relatives $T$. turgidum [GenBank:KR559878] (AABB), $T$. monococcum [KR559879] ( $\mathrm{A}^{\mathrm{m}} \mathrm{A}^{\mathrm{m}}$, A-relative), Ae. speltoides [KR559880] (SS, B-relative), and Ae. tauschii [KR559881] (DD) (Figs. 1 and 6; Additional File 2). Note that only a single consensus sequence was derived from the tetraploid $T$. turgidum. The TaEPSPS-7D1 cDNA clone was in the same clade as Ae. tauschii, consistent with evidence that the D-genome was incorporated into allohexaploid wheat fairly recently [9]. TaEPSPS-4A1 was most closely related to the $\mathrm{B}$-genome relative $A e$. speltoides, consistent with our interpretation that TaEPSPS-4A1 is the B-genome copy of EPSPS, likely located within the 7BS translocation to chromosome 4AL. Interestingly, EPSPS from the A-genome relative T. monococcum is more closely related to TaEPSPS-4A1 than to TaEPSPS-7A1. TaEPSPS-7A1 was very closely related to the cDNA cloned from tetraploid T. turgidum $(0.0026$ genetic distance).

Phylogenetic analysis indicated that the TaEPSPS-7A1 and TaEPSPS-7D1 genes are most closely related to those of the most recent progenitors, tetraploid T. turgidum (99.7 \% identity) and diploid Ae. tauschii (100\% identity), respectively. TaEPSPS-7A1 is more closely related to the EPSPS cloned from $T$. turgidum (AABB) than from the A-genome donor relative T. monococcum (96.1\% identity) or the B-genome relative Ae. speltoides (97.1\% identity). TaEPSPS-4A1, however, is more closely related to the B-genome relative Ae. speltoides (97.7\% identity) than to $T$. turgidum (96.8 \% identity), and is consistent with previous analyses concluding that homoeologues of $T$. aestivum (AABBDD) are more closely related to homologues in Ae. tauschii (DD) and T. turgidum $(\mathrm{AABB})$ than to the primitive $\mathrm{A}$ - and $\mathrm{B}$-genome ancestors $[7,21]$. It appears that the diploid A- and B-genome progenitors of allohexaploid wheat have evolved independently from $T$. turgidum following the tetraploidization event, whereas the D-genome donor Ae. tauschii is still very closely related to the $\mathrm{D}$-genome of $T$. aestivum [reviewed by 27]. Moreover, T. monococcum has evolved independently from $T$. turgidum since its last shared ancestor with the wild einkorn A-genome progenitor $T$. urartu. The genetic variation in the wheat A- and Bgenome EPSPS homoeologues appears to have resulted from the accumulation of point mutations, small DNA insertions/deletions, and genetic recombination, likely following the polyploidization event (Fig. 1; Additional files 2 and 3) [reviewed in 9, 27].

The phylogenetic relationship of the three wheat EPSPS 1190-bp cDNA sequences was also examined compared to the corresponding sequence in other grasses using the $\operatorname{dicot} A$. thaliana as the outgroup (Fig. 7). The three TaEPSPS genes were most closely related to EPSPS of L. multiflorum and B. distachyon and more distantly related to EPSPS of rice. The remaining clade includes monocots $Z$. mays, S. halepense, and Eleusine indica.

Allohexaploid wheat, L. multiflorum, and model plant B. distachyon are believed to have originated from a common ancestor that diverged from rice about 46 million years ago (MYA), whereas the grasses in general are believed to have shared a common ancestor about 90 MYA [36, 37]. A comparative genome analysis between wheat and $B$. distachyon suggested that these two species diverged at 32-39 MYA [38]. Moreover, analysis of 


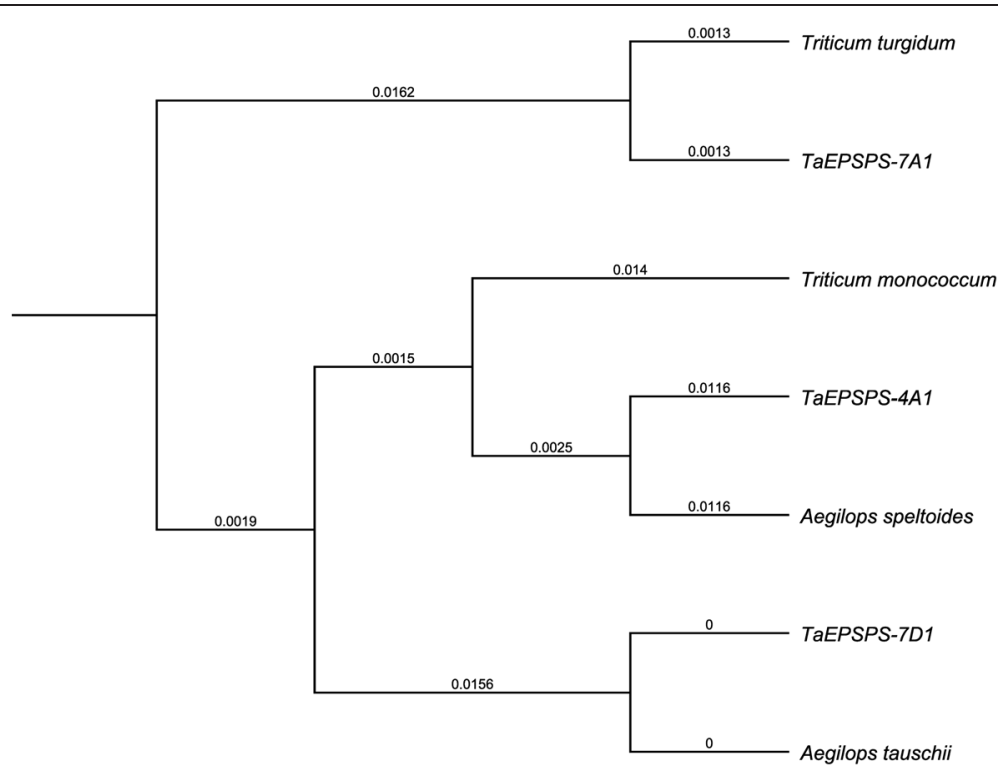

Fig. 6 Phylogenetic tree of EPSPS genes of wheat and wheat relatives. The UPGMA method was used to analyze nucleotide sequence similarity based on the 1190-bp cDNA sequences. Numbers at each branch indicate the genetic distance

acetyl-CoA carboxylase (ACCase) and 3-phosphoglycerate kinase $(P G K)$ genes between wheat and ryegrass $(L$. rigidum) revealed that they diverged about 35 MYA [7].

\section{Conclusions}

The study reports the cloning, sequencing, and mapping of three homoeologous EPSPS genes named TaEPSPS$7 A 1$ [GenBank:KP411547], TaEPSPS-7D1 [KP411548], and TaEPSPS-4A1 [KP411549] from allohexaploid wheat cultivar 'Louise'. The genes were located on chromosomes 7AS, 4AL (translocated from 7BS), and 7DS, respectively. The comparison of cDNA and genomic DNA sequences allowed confirmation of the intron/exon structure, as well as the development of genome-specific primers. RT-qPCR analysis revealed that all three EPSPS homoeologues are actively transcribed. However, TaEPSPS-7A1 had the

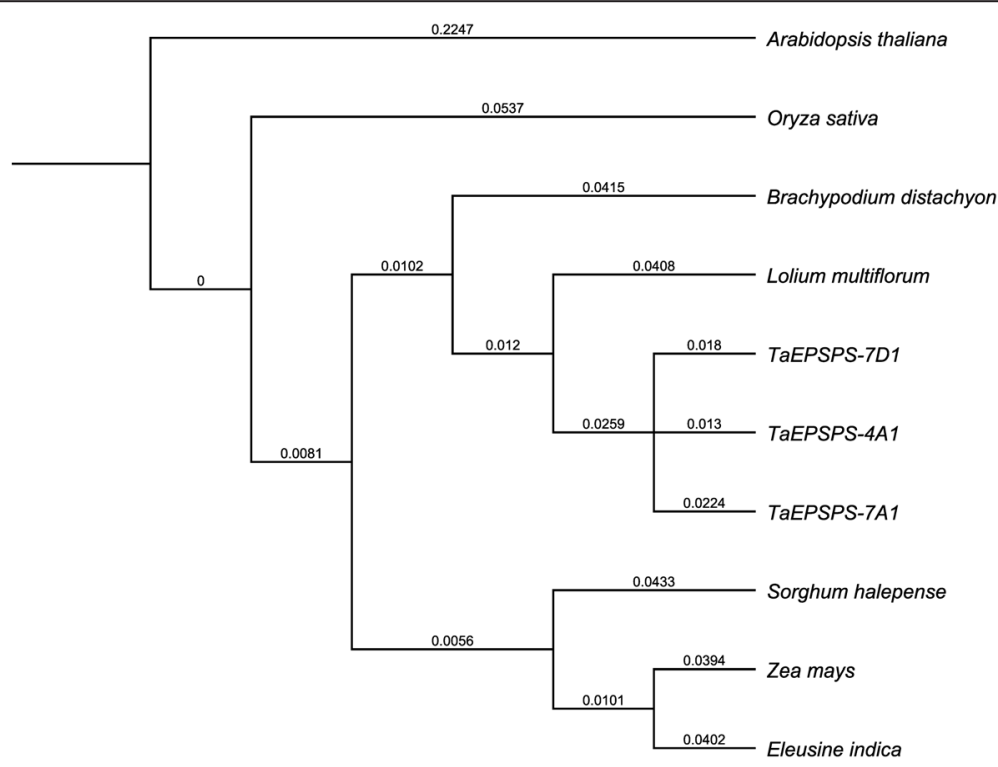

Fig. 7 Phylogenetic tree of EPSPS genes of grass species. The 1190-bp cDNA sequences of TaEPSPS-7A1, TaEPSPS-4A1, and TaEPSPS-7D1 from allohexaploid wheat 'Louise' were compared to the corresponding EPSPS sequences from other species using the Neighbor-Joining method with the dicot $A$. thaliana as the outgroup. Numbers at each branch represent the genetic distance. The EPSPS homologues include A. thaliana [GenBank:NM_130093], B. distachyon [XM_003557194], E. indica [HQ403647], S. halepense [HQ436353], Z. mays [X63374], O. sativa [AF413081], and L. multiflorum [DQ153168] 
highest level of expression in young leaves. The three EPSPS genes had a high degree of sequence conservation at both the cDNA and protein levels. Phylogenetic analysis suggests that the EPSPS of wheat is closely related to EPSPS of L. multiflorum and B. distachyon.

\section{Methods}

Plant material and growth conditions

Grains of $T$. aestivum soft white spring 'Louise' (AABBDD, Reg. No. CV-987, PI 634865) [39] and of wheat relatives $[T$. turgidum ssp. dicoccoides (AABB), $T$. monococcum DV92 ( $\mathrm{A}^{\mathrm{m}} \mathrm{A}^{\mathrm{m}}$, A-relative) [40], Ae. speltoides (SS, B-relative), and Ae. tauschii (DD)] were grown in a greenhouse at $21-24{ }^{\circ} \mathrm{C}$ daytime and $15-17{ }^{\circ} \mathrm{C}$ nighttime with a 16-h day/8-h night photoperiod (Wheat Growth Facility, Washington State University, Pullman WA). At the 3 to 5-leaf stage, young leaf tissue was harvested, submerged in liquid nitrogen, and stored at $-80{ }^{\circ} \mathrm{C}$. Frozen leaf tissue was ground to a fine powder with a cold mortar and pestle under liquid nitrogen and stored at $-80{ }^{\circ} \mathrm{C}$ until use for nucleic acid extraction.

\section{Nucleic acid isolation and CDNA synthesis}

Louise genomic DNA was isolated from $100 \mathrm{mg}$ of ground leaf tissue using the sodium bisulfite method $[41,42]$. Total RNA was extracted using the Trizol reagent (Invitrogen) method according to the manufacturer's protocol. Before performing RT-qPCR, RNA samples were treated with $2 \mathrm{U}$ of DNase I to prevent DNA contamination using the DNA-free RNA kit ${ }^{\text {tw }}$ (Zymo Research). Nucleic acid concentration and quality were assessed by NanoDrop ${ }^{\mathrm{Tx}}$ UV spectrophotometry and by agarose gel electrophoresis. For the cDNA cloning experiment, first-strand cDNA was synthesized from $5 \mu \mathrm{g}$ of total RNA using the ImProm- $\mathrm{II}^{\mathrm{TN}}$ reverse transcription system kit (Promega) according to the manufacturer's instructions. For the RT-qPCR experiment, first-strand cDNA was synthesized from $1 \mu \mathrm{g}$ of total RNA using the ProtoScript ${ }^{\circ}$ first strand cDNA synthesis kit (NEB) following the manufacturer's instructions. Synthesized cDNA was adjusted to a final concentration of $100 \mathrm{ng} / \mu \mathrm{l}$ for cDNA cloning and to $2 \mathrm{ng} / \mu \mathrm{l}$ with RNase-free water for RT-qPCR experiments.

\section{Primer design}

Primers designed to either amplify all copies or a specific copy of the TaEPSPS cDNA were based on a sequence alignment of a $T$. aestivum Chinese Spring cDNA consensus sequence [GenBank: EU977181], with T. aestivum ESTs [DR740760, CJ674666, CJ962197, CJ567699, CJ565347, CJ9534710, CJ653434, BQ743545, BG605080, BF483288, CD889643, and EB513993], and T. monococcum ESTs [BF200451 and BF199999] (Table 1). Genome-specific primers used to amplify both cDNA and genomic DNA were based on cDNA alignments of the 1190-bp cDNA clones from Louise wheat, and from the wheat relatives $T$. monococcum, T. turgidum, Ae. speltoides, and Ae. tauschii (Table 1; Additional file 2). Both primers used for gene cloning and genome-specific primers used for mapping and RT-qPCR were derived from alignments of cDNA and genomic DNA sequences of TaEPSPS-7A1, TaEPSPS-7D1, and TaEPSPS-4A1 (Table 1; Additional files 1, 3 and 4). The genome-specificity of primers was checked using amplification of cDNA from wheat progenitors and genomic DNA from nulli-tetrasomic lines.

\section{PCR and IPCR amplification}

PCR amplification was performed as follows: 1) 1 cycle of $94{ }^{\circ} \mathrm{C}$ for $5 \mathrm{~min}$; 2) 35 cycles of $94{ }^{\circ} \mathrm{C}$ for $1 \mathrm{~min}$, annealing for $20-40 \mathrm{~s}$, and extension at $72{ }^{\circ} \mathrm{C}$ for $1 \mathrm{~min} / \mathrm{kb}$, and 3) 1 cycle of $10 \mathrm{~min}$ at $72{ }^{\circ} \mathrm{C}$ for the final extension. The optimized annealing temperatures and the extension times are provided in Additional file 1. Unless otherwise indicated, PCR reactions generally contained: 1) 50-60 ng gDNA or 200 ng cDNA template, 2) $0.2 \mathrm{mM}$ dNTPs, $2 \mathrm{mM} \mathrm{MgCl}_{2}$, 3) $0.4 \mu \mathrm{M}$ of each primer, 4) $1 \mathrm{X}$ Mango buffer (Bioline), and 5) $0.5 \mathrm{U}$ of either Mango Taq enzyme (Bioline) or of the proofreading enzymes $L A T a q$ or $E x$ Taq (TaKaRa) depending on the application.

PCR amplification of the GC-rich 5'-region (exon 1) of the TaEPSPS-7A1 gene were optimized using a panel of buffers designed for amplification of difficult templates (Fig. 2; Additional file 3). The PCR reactions contained $0.2 \mu \mathrm{M}$ of F1.2 and R1 primers, $1 \mathrm{U}$ proofreading $E x$ Taq DNA polymerase (TaKaRa), and $1 \mathrm{X}$ each of the following premixed commercial buffers: GCI and GCII with $2 \mathrm{mM} \mathrm{MgCl}{ }_{2}$ (TaKaRa), and Buffers D, E, F, G, H, and I (Epicentre $^{\mathrm{Tm}}$ ). The reactions were also supplemented with DMSO at $0 \%, 2.5 \%, 5 \%$, and $7.5 \%$ in each buffer $[43,44]$. The 3.3-kb TaEPSPS-7A1 clone was successfully recovered using buffer D and $5 \%$ DMSO, and sequenced in both the forward and reverse directions (Table 1).

Inverse PCR (IPCR) was used to clone unknown sequences of TaEPSPS-7D1 and TaEPSPS-4A1 genes (Table 1; Additional files 1 and 4). IPCR was performed using, $1.5 \mu \mathrm{g}$ of Louise gDNA digested with restriction enzymes HindIII and AccI (10 U, Thermo Scientific) at $37^{\circ} \mathrm{C}$ for $2 \mathrm{~h}$. After heat inactivation at $80^{\circ} \mathrm{C}$ for $20 \mathrm{~min}$, DNA fragments were gel-purified using the QIAEX II gel extraction kit. The DNA fragments were diluted to $4 \mathrm{ng} / \mu \mathrm{l}$ then selfligated into circular DNA by incubating with T4. DNA ligase (NEB Biolabs) at $16{ }^{\circ} \mathrm{C}$ for $16 \mathrm{~h}$. The circularized DNA was again gel purified and diluted to $10 \mathrm{ng} / \mu \mathrm{l}$. Genomic DNA without enzyme digestion served as a control for detecting artifactual fragments. The first round of IPCR was carried out in $20 \mu \mathrm{l}$ of reaction mixture containing $40 \mathrm{ng}$ of circularized gDNA, $0.4 \mu \mathrm{M}$ of primers InvF1-AB/D-InvR1-AB/D for TaEPSPS-4A1 or 
F19-D-R18-D for TaEPSPS-7D1, $0.2 \mathrm{mM}$ dNTPs, $2 \mathrm{mM} \mathrm{MgCl}_{2}, 1 \mathrm{X} \mathrm{GCI}$ buffer (TaKaRa), and $1 \mathrm{U} L A$ Taq polymerase (TaKaRa). One microliter of the first round PCR reaction was used as a template in the second round of IPCR using the same conditions but for substitution of $1 \mathrm{U}$ Mango Taq DNA polymerase and buffer (Bioline) for the enzyme and use of the primers InvF3-AB/D-InvR2-AB/D for TaEPSPS-4A1 and F18-D-R18-D for TaEPSPS-7D1.

\section{DNA cloning and sequencing}

In order to obtain multiple independent clones, the PCR and IPCR reactions were aliquoted into at least 3 separate tubes before performing PCR. PCR products were separated and visualized on a $\mathrm{SYBR}^{\odot}$ Safe (Invitrogen)-stained 0.8 to $2 \%$ agarose gel depending on the expected amplicon size. For cloning, gel-excised DNA fragments were purified using the QIAEX II gel extraction kit (Qiagen), and ligated into the pGEM-T easy vector (Promega). Ligation reactions were transformed into $E$. coli, and plasmids with insertion were selected by blue-white screening and confirmed by PCR. Clones were then isolated for the plasmids. Plasmid DNA clones prepared using the QIAprep miniprep kit (Qiagen) were sequenced in both the forward and reverse directions using either Elim Biopharmaceuticals, Inc. (Hayward, CA) or the Molecular Biology and Genomics Core (WSU, Pullman) sequencing services.

Mapping the location of EPSPS genes in hexaploid wheat PCR amplification using genomic DNA of nulli-tetrasomic lines (NA-TD, NB-TD, and ND-TB) in Chinese Spring wheat was used to check primer specificity and to determine which EPSPS gene was located on which wheat chromosome (Table 1; Additional file 1). Nulli-tetrasomic Chinese Spring genotypes contain four copies of one chromosome pair (tetrasomic) to compensate for lack of a homoeologous chromosome pair (nullisomic) [45]. For instance, Nulli1A-Tetra1D (N1AT1D) lacks chromosome 1A (nullisomic-1A), but contains two chromosome pairs of chromosome 1D (tetrasomic-1D), resulting a line containing no copies of chromosome $1 \mathrm{~A}$, two doses of chromosome 1B, and four doses of chromosome 1D. PCR analysis of genomic DNA from nulli-tetrasomic lines allows one to determine which chromosome a gene is located on based on failure to amplify in specific nullisomic lines [16]. For example, if a gene is located on chromosome $1 \mathrm{~A}$, the PCR product will not be generated in the N1AT1D or N1AT1B template when 1A genome-specific primers are used. PCR amplification was performed as described above and repeated three times for each primer pair.

Quantitative Reverse Transcription-PCR (RT-qPCR) analysis One microliter of the cDNA reaction was used as a template in the RT-qPCR reaction. Real-time quantitative
PCR was performed using the LightCycler FastStart DNA Master SYBR Green I Kit on a LightCycler carousel-based system (Roche). The cDNA synthesized from six biological replicates was used to perform in RT-qPCR with two technical replications for each sample of each primer pair. The constitutive transcript of the protein transport gene $\operatorname{Sec} 23 A$ ( $T a S E C$ ) was used for normalization to compensate for small variations in the input RNA amounts and cDNA synthesis efficiency among samples [46]. The expression levels of TaEPSPS-7A1, TaEPSPS-7D1, and TaEPSPS-4A1 in hexaploid wheat were determined by genome-specific primers (Additional file 1). Each PCR reaction consisted of $1 \mu \mathrm{l}$ of template, $0.5 \mu \mathrm{M}$ primer pair, $3 \mathrm{mM} \mathrm{MgCl}_{2}$, but $2 \mathrm{mM}$ for TaEPSPS-7D1, and 1X FastStart DNA Master SYBR Green I reagent (Roche) in a total volume of $10 \mu \mathrm{l}$. The amplification program was $95{ }^{\circ} \mathrm{C}$ for $10 \mathrm{~min}$ followed by 50 cycles of $95{ }^{\circ} \mathrm{C}$ for $10 \mathrm{~s}, 5 \mathrm{~s}$ at the specific annealing temperature (Additional file 1 ), and $72{ }^{\circ} \mathrm{C}$ for $10 \mathrm{~s}$. After amplification, amplicon melting profiles were generated ranging over 70 $-96{ }^{\circ} \mathrm{C}$ to assess PCR specificity. A 2-fold serial dilution of genomic DNA or cDNA samples was used to construct a standard curve to determine amplification efficiency (99.06-106.02 \%). Relative fold-change of EPSPS was determined using the comparative $\mathrm{Cq}$ or $2^{-\Delta \Delta \mathrm{Cq}}$ method [47], where $\mathrm{Cq}=\mathrm{Cq}($ TaEPSPS $)-\mathrm{Cq}($ TaSEC $)$ and $\mathrm{Cq}=$ Cq(TaEPSPS-7A1 or $-7 D 1)$ - Cq (TaEPSPS-4A1 used as a calibrator for comparisons). Total RNA without reverse transcription (no RT) was used as a negative control to screen for gDNA contamination. No template controls were included for each real-time PCR run to screen for contamination of reagents.

\section{Data analysis}

Sequence alignments were generated using ClustalW (http://www.genome.jp/tools/clustalw/) and Geneious ${ }^{\mathrm{Tm}}$ software. Amino acid sequences were deduced using ExPaSy (http://web.expasy.org/translate/.). For RT-qPCR, the mean values of EPSPS fold change of each genomic copy were compared by statistical analysis using a oneway general analysis of variance (ANOVA) algorithm with Tukey's comparison at the significance level of 0.01 (SAS version 9.3). Phylogenetic trees were constructed under the genetic distance model of Tamura-Nei, where numbers indicate the genetic distance [48]. The cladograms were generated using Geneious ${ }^{\mathrm{TM}}$ software based on analysis with the UPGMA (rooted) algorithm for phylogeny for Fig. 6 or with the Neighbor-Joining (unrooted) algorithm with the bootstrap test (1000 replicates) for Fig. 7 $[49,50]$.

\section{Availability of supporting data}

The data sets supporting the results of this article are included within the article and its additional files. 


\section{Additional files}

\section{Additional file 1: Combinations of primer pairs for particular purposes and conditions for PCR amplification. (PDF $81 \mathrm{~kb}$ )}

Additional file 2: A nucleotide sequence alignment of EPSPS CDNA clones from allohexaploid wheat and wheat progenitors. (PDF $312 \mathrm{~kb}$ )

Additional file 3: Nucleotide sequence alignment and primer positions. (PDF $169 \mathrm{~kb}$ )

Additional file 4: The EPSPS genomic DNA cloning strategy. (PDF $245 \mathrm{~kb}$ )

Additional file 5: Amino acid sequence alignment of wheat EPSPS. (PDF $47 \mathrm{~kb}$ )

Additional file 6: Conservation of the predicted signal peptide cleavage site. (PDF $69 \mathrm{~kb}$ )

\section{Competing interests}

The authors declare that they have no competing interests.

\section{Authors' contributions}

CMS, KKK, ICB, and AA designed the experiments; AA performed the experiments and analyzed the data; AA, CMS, and ICB wrote the paper. All authors read and approved the final manuscript.

\section{Acknowledgments}

The authors would like to thank members of the Burke and Steber laboratories for helpful advice and support, and thank Dr. Arron Carter for helpful comments on the manuscript. Thanks are due to Keiko Tuttle and Dr. Patricia Okubara for assistance with RT-qPCR and data analysis. Thanks are also due to Dr. Deven See for providing nullisomic-tetrasomic wheat lines and advice for their use. This research was supported by the Washington State University Foundation (to KKK and ICB), and by the USDA-ARS (to CMS).

\section{Author details}

${ }^{1}$ Department of Crop and Soil Science, Washington State University, Pullman, WA, USA. ${ }^{2}$ Wheat Genetics, Quality, Physiology and Disease Research, USDA-ARS, Pullman, WA, USA.

Received: 8 May 2015 Accepted: 14 October 2015

Published online: 23 October 2015

\section{References}

1. Geiger DR, Fuchs MA. Inhibitors of aromatic amino acid biosynthesis (glyphosate). In: Boger P, Wakabayashi K, Hirai K, editors. Herbicide classes in development: Mode of action, targets, genetic engineering, chemistry. New York: Springer; 2002. p. 59-85.

2. Cobb AH, Reade JPH. The inhibition of amino acid biosynthesis. In: Cobb $\mathrm{AH}$, Reade JPH, editors. Herbicides and plant physiology. 2nd ed. New Jersey: Wiley-Blackwell; 2010. p. 126-44.

3. $\mathrm{Ng} \mathrm{CH}$, Wickneswari R, Salmijah S, Teng YT, Ismail BS. Gene polymorphisms in glyphosate-resistant and -susceptible biotypes of Eleusine indica from Malaysia. Weed Res. 2003;43:108-15.

4. Kaundun SS, Dale RP, Zelaya IA, Dinelli G, Marotti I, McIndoe E, et al. A nove P106L mutation in EPSPS and an unknown mechanism(s) act additively to confer resistance to glyphosate in a South African Lolium rigidum population. J Agric Food Chem. 2011;59:3227-33.

5. Yu Q, Cairns A, Powles S. Glyphosate, paraquat and ACCase multiple herbicide resistance evolved in a Lolium rigidum biotype. Planta. 2007;225:499-513.

6. Yuan Cl, Chaing MY, Chen YM. Triple mechanisms of glyphosate-resistance in a naturally occurring glyphosate-resistant plant Dicliptera chinensis. Plant Sci. 2002;163:543-54

7. Huang S, Sirikhachornkit A, Su X, Faris J, Gill B, Haselkorn R, et al. Genes encoding plastid acetyl-CoA carboxylase and 3-phosphoglycerate kinase of the Triticum/Aegilops complex and the evolutionary history of polyploidy wheat. Proc Natl Acad Sci. 2002;99:8133-8.

8. Gu YQ, Coleman-Derr D, Kong X, Anderson OD. Rapid genome evolution revealed by comparative sequence analysis of orthologous regions from four Triticeae genomes. Plant Physiol. 2004;135:459-70.
9. Feldman M, Levy AA. Genome evolution due to allopolyploidization in wheat. Genetics. 2012;192:763-74.

10. Sears ER. Genetic control of chromosome pairing in wheat. Ann Rev Genet. 1976;10:31-51.

11. Devos KM, Dubcovsky J, Dvorak J, Chinoy CN, Gale MD. Structural evolution of wheat chromosome $4 \mathrm{~A}, 5 \mathrm{~A}$, and $7 \mathrm{~B}$ and its impact on recombination. Theor Appl Genet. 1995;91:282-8.

12. Wanjugi H, Coleman-Derr D, Huo N, Kianian SF, Luo MC, Wu J, et al. Rapid development of PCR-based genome-specific repetitive DNA junction markers in wheat. Genome. 2009:52:576-87.

13. Schonbrunn E, Eschenburg S, Shuttleworth WA, Schloss JV, Amrhein N Evans JNS, et al. Interaction of the herbicide glyphosate with its target enzyme 5-enolpyruvylshikimate-3-phosphate synthase in atomic detail. Proc Natl Acad Sci. 2001:98:1376-80.

14. Barry GF, Kishore KGM, Padgette SR, Stallings WC. For selectively controlling weeds in a planted transgenic crop field (US 5633435 A). 1997. http://www.google.com/patents/US5633435. Accessed 24 Feb 2015.

15. Ciaffi M, Paolacci AR, D'Aloisio E, Tanzarella OA, Porceddu E. Cloning and characterization of wheat PDI (protein disulfide isomerase) homoeologous genes and promoter sequences. Gene. 2006;366:209-18.

16. Ohnishi N, Himi E, Yamasaki Y, Noda K. Differential expression of three ABAinsensitive five binding protein (AFP)-like genes in wheat. Genes Genet Syst. 2008:83:167-77.

17. Devisetty UK, Mayes K, Mayes S. The RAD51 and DMC1 homoeologous genes of bread wheat: cloning, molecular characterization and expression analysis. BMC Res Notes. 2010;3:245.

18. The International Wheat Genome Sequencing Consortium (IWGSC). A chromosome-based draft sequence of the hexaploid bread wheat (Triticum aestivum) genome. Science. 2014; 345:1251788. doi:10.1126/science.1251788.

19. Schreiber AW, Hayden MJ, Forrest KL, Kong SL, Langridge P, Baumann U Transcriptome-scale homoeolog-specific transcript assemblies of bread wheat. BMC Genomics. 2012;13:492

20. Leach LJ, Belfield EJ, Jiang C, Brown C, Mithani A, Harberd NP. Patterns of homoeologous gene expression shown by RNA sequencing in hexaploid bread wheat. BMC Genomics. 2014;15:276.

21. Huang $X Q$, Anita BB. Development of genome-specific primers for homoeologous genes in allopolyploid species: the waxy and starch synthase II genes in allohexaploid wheat (Triticum aestivum L.) as examples. BMC Res Notes. 2010;3:140.

22. Ochman H, Gerber AS, Hartl DL. Genetic application of an inverse polymerase chain reaction. Genetics. 1988;120:621-3.

23. Feng DS, Wang HG, Zhang XS, Kong LR, Tian JC, Li XF. Using an inverse PCR method to clone the wheat cytokinin oxidase/dehydrogenase gene TaCKX1. Plant Mol Biol Rep. 2008;26:143-55.

24. Qi L, Echalier B, Friebe B, Gill BS. Molecular characterization of a set of wheat deletion stocks for use in chromosome bin mapping of ESTs. Funct Integr Genomics. 2003;3:39-55.

25. Garg B, Vaid N, Tuteja N. In-silico analysis and expression profiling implicate diverse role of EPSPS family genes in regulating developmental and metabolic processes. BMC Res Notes. 2014;7:58.

26. Pumphrey M, Bai J, Laudencia-Chingcuanco D, Anderson O, Gill BS. Nonadditive expression of homoeologous genes is established upon polyploidization in hexaploid wheat. Genetics. 2009;181:1147-57.

27. Wendel JF. Genome evolution in polyploids. Plant Mol Biol. 2000;42:225-49.

28. He P, Friebe BR, Gill BS, Zhou JM. Allopolyploidy alters gene expression in the highly stable hexaploid wheat. Plant Mol Biol. 2003;52:401-14.

29. Veitia RA. Paralogs in polyploids: One for all and all for one? Plant Cell. 2005;17:4-11.

30. Gaines TA, Wright AA, Molin WT, Lorentz L, Riggins CW, Tranel PJ, et al. Identification of genetic elements associated with EPSPS gene amplification. PLoS One. 2013;8, e65819.

31. Heijne GV, Steppuhn J, Herrmann RG. Domain structure of mitochondrial and chloroplast targeting peptides. Eur J Biochem. 1989;180:535-45.

32. Petsalaki El, Bagos PG, Litou ZI, Hamodrakas SJ. PredSL: a tool for the $\mathrm{N}$-terminal sequence-based prediction of protein subcellular localization. Genomics Proteomics Bioinformatics. 2006:4:48-55.

33. Hebsgaard SM, Korning PG, Tolstrup N, Engelbrecht J, Rouze P, Brunak S. Splice site prediction in Arabidopsis thaliana DNA by combining local and global sequence information. Nucleic Acids Res. 1996;24:3439-52.

34. Reese MG, Eeckman FH, Kulp D, Haussler D. Improved splice site detection in genie. J Comp Biol. 1997:4:311-23. 
35. Junwang X, Dejiang F, Xugang L, Tuanjie C, Zhen Z. Cloning of genomic DNA of rice 5-enolpyruvylshikimate-3-phosphate synthase gene and chromosomal localization of the gene. Sci China. 2002;45:251-9.

36. Gaut BS. Evolutionary dynamics of grass genomes. New Phytol. 2002;154:15-28.

37. Salse J, Bolot S, Throude M, Jouffe V, Piegu B, Quraishi UM, et al. Identification and characterization of shared duplications between rice and wheat provide new insight into grass genome evolution. Plant Cell. 2008;20:11-24.

38. The International Brachypodium Initiative (IBI). Genome sequencing and analysis of the model grass Brachypodium distachyon. Nature. 2010;463:763-8

39. Kidwell KK, Shelton GB, Demacon VL, Burns JW, Carter BP, Chen XM, et al. Registration of 'Louise' Wheat. Crop Sci. 2006. doi:10.2135/cropsci 2005.06-0176.

40. Lijavetzky D, Muzzi G, Wicker T, Keller B, Wing R, Dubcovsky J. Construction and characterization of a bacterial artificial chromosome (BAC) library for the A genome of wheat. Genome. 1999:42:1176-82.

41. Anderson JA, Ogihara Y, Sorrells ME, Tanksley SD. Development of a chromosomal arm map for wheat based on RFLP markers. Theor Appl Genet. 1992;83:1035-43.

42. Tai TH, Tanksley SD. A rapid and inexpensive method for isolation of total DNA from dehydrated plant tissue. Plant Mol Biol Rep. 1990;8:297-303.

43. Frackman S, Kobs G, Simpson D, Storts D. Betaine and DMSO: Enhancing agents for PCR. Promega Notes. 1998;65:27.

44. Jensen MA, Fukushima M, Davis RW. DMSO and betaine greatly improve amplification of GC-rich constructs in De Novo Synthesis. PLoS One. 2010;5:e11024.

45. Sears ER. nullisomic-tetrasomic combinations in hexaploid wheat. In: Riley R, Lewis KR, editors. Chromosome Manipulations and Plant Genetics. New York: Plenum Press; 1966. p. 29-45.

46. Paolacci AR, Tanzarella OA, Porceddu E, Ciaffi M. Identification and validation of reference genes for quantitative RT-PCR normalization in wheat. BMC Mol Biol. 2009;10:11.

47. Livak KJ, Schmittgen TD. Analysis of relative gene expression data using real-time quantitative PCR and the $2^{-\mathrm{Ct}}$ method. Methods. 2001;25:402-8.

48. Takezaki N, Nei M. Genetic distances and reconstruction of phylogenetic trees from microsatellite DNA. Genetics. 1996;144:389-99.

49. Saitou N, Nei M. The neighbor-joining method: a new method for reconstructing phylogenetic trees. Mol Biol Evol. 1987;4:406-25.

50. Efron B, Halloran E, Holmes S. Bootstrap confidence levels for phylogenetic trees. Proc Natl Acad Sci. 1996;93:13429-34.

\section{Submit your next manuscript to BioMed Central and take full advantage of:}

- Convenient online submission

- Thorough peer review

- No space constraints or color figure charges

- Immediate publication on acceptance

- Inclusion in PubMed, CAS, Scopus and Google Scholar

- Research which is freely available for redistribution

Submit your manuscript at www.biomedcentral.com/submit 